\title{
Agencies warn of grant delays as Washington returns to backlog
}

Washington. A three-week shutdown of large parts of the US federal government ended this week, leaving science agencies warning of months of delays and uncertainty as their administrative staff returned to face huge backlogs of grant processing and other work.

Nature compounded the shambles at the Washington headquarters of the National Institutes of Health (NIH), the National Science Foundation (NSF) and the National Aeronautics and Space Administration (NASA) on Monday, when 18 inches of snow pushed the anticipated reopening back to the middle of this week.

The unprecedented three-week shutdown ended with a retreat by Republican congressmen, who were being blamed by the public for the disruption that it was causing. Last Friday, 5 January, the Republicans changed their strategy and passed bills to reopen the government, despite failing to reach agreement with President Bill Clinton on how to balance the government's budget.

For the NIH, the shutdown ended with an unexpected financial windfall. One of three 'continuing resolution' bills passed into law at the weekend will assure the biomedical research agency of funding to the end of the fiscal year, 30 September, of almost $\$ 11.5$ billion, up by 5.7 per cent from last year.

$\mathrm{NIH}$ and the Centers for Disease Control, based in Atlanta, Georgia, are included in a bunch of 'targeted programmes' which Congress decided should no longer be held hostage to budget negotiations. NSF and NASA failed to make the list, and are assured of funding - at the levels of the last financial year - only until 25 January, when the threat of yet another shutdown looms.

\section{CERN greets detection of first anti-atom}

London. An announcement last week by the European Laboratory for Particle Physics (CERN) that its physicists have created antihydrogen - the first detected antiatom - has set the stage for a new type of experiment designed to test fundamental physical principles.

Those tests, which still require further experimental development, will cause an even greater stir if, contrary to most physicists' expectations, the principles namely the equivalence principle (EP) and universal compliance with charge-parity-time (CPT) symmetry - are overturned.

The CERN physicists, headed by Walter Oelert of the Institute of Nuclear Physics at the National Research Centre in Jülich, brought together antiprotons and positrons in CERN's Low Energy Antiproton Ring (LEAR, above right). By studying the resulting particles ejected from the ring, the researchers were able to confirm that anti-hydrogen had been formed, albeit fleetingly.

The next challenge, to be pursued in other facilities, will be to carry out extremely precise spectroscopic measurements of the energy levels of anti-atoms, in order to look for differences between hydrogen and

\section{IMAGE UNAVAILABLE FOR COPYRIGHT REASONS}

anti-hydrogen spectra.

Such spectroscopy requires the development of anti-atom 'traps'. This is unlikely to be achieved at CERN before late 1998 - and then only if physicists can find about SFr7 million (US\$6 million) from external sources required to develop the necessary equipment. Meanwhile, physicists at Fermilab are hoping to carry out even more challenging spectroscopy of beams of anti-hydrogen atoms within a year or so.

Philip Campbell
Grant processing at all of these agencies has been at a standstill now for almost a month, holding up hundreds of millions of dollars of funds for university research. At the NIH, 2,000 grants due to start or be renewed on 1 December and 1 January have not been issued. NIH officials say they are uncertain how quickly the return to work will enable the processing of these and a further 2,000 grants due on 1 February.

Harold Varmus, the director of the NIH, says even with assured funding for the rest of the year, the shutdown will have "a very significant fallout". NIH has "a very tightly orchestrated system" to process 30,000 grants a year. He appealed to grant recipients to be patient with NIH staff as they seek to get the process back on schedule.

Neal Lane, director of the NSF, says that the agency, which funds most non-biomedical university science in the United States, has delayed $\$ 100$-million worth of awards, and that this has been growing at a rate of $\$ 10$ million a day. "There's no way that we'll get through the backlog quickly," says Lane, who noted last Friday there were 42 large carts of mail in his mailroom.

After the agency failed to make the list of targeted programmes, another senior NSF official attacked universities for failing to complain loudly enough on its behalf. The NSF got "zero help" from academics in its bid to make the list, the official said. Asked how quickly NSF would clear its backlog, the official pointed to the looming threat of another shutdown on 25 January. "I don't know what we can do 'quickly'," he said. "We've got a two-week window to do ten weeks of work."

Most major universities have tried to ease the impact of the shutdown on researchers by providing temporary funds to enable the continuation of research for which grant support has been delayed. The Massachusetts Institute of Technology, for example, had last week committed \$11.5 million a year, or about $\$ 1$ million a month, to supporting such projects.

Mike Amey, assistant dean for research administration at the school of medicine at Johns Hopkins University, Baltimore, says the impact of the three-week shutdown is hard to calculate, because of the holiday season and the normally slow start to the financial year. "It's not that we are not feeling the pinch," he says. "But it is too soon to know how big the impact is, as there is normally a delay at this time of year."

NASA employees also returned to a huge backlog of paperwork this week, which 